\title{
Evaluadores Número 7
}

\section{Gabriel Álvarez}

Liliana Palacios de Cosiansi

Ana Fernández

Mónica García

Néstor Gómez

Santiago Linares

Patricia Lucero

Julio Kelly

Sergio Naessens

Liliana Ramírez

Norma del Río Lugo

Lía Rodríguez de la Vega

Karla Valverde Viesca

María Laura Zulaica 